\title{
Numerical Simulation for Orbit Patterns of Three Stars
}

\author{
M.Y. Zhou \\ Jiangsu Tianyi High School \\ China \\ R.H. Yao \\ Jiangsu Tianyi High School \\ China
}

\begin{abstract}
After surveying and analyzing the educational condition of the High- School Physics, specifically about the stars' movements, we treated the High-School Physics material as basis, researched enormous information from the internet and simulated three stars' movements depending on numerical method, and created the moving orbits for distinct patterns of three stars by writing a program in MATLAB ${ }^{[1]}$.Our research tried to simulate different orbit patterns of three stars' movement in one single plane. This paper talks about the process of our research, including program-creating, formula-deriving and situation discussion of the three stars' movements, as well as applications in reality.
\end{abstract}

Keywords- celestial movement; numerical simulation; difference equation; orbit patterns; matrix laboratory ${ }^{[2]}$

\section{INTRODUCTION}

The famous Astrophysics scientist, Poincare proved that there are no fixed solutions for the three bodies' problem as the two bodies' problem ${ }^{[2]}$ does. We decided to simulate distinct patterns of the three stars' movements in two-dimensions using the extremely versatile engineering software MATLAB. We use the trapezoid method in writing the codes. While simulating each pattern, we need to decide the initial positions and velocities, obeying the Conservation Law of momentum and energy. So far, we've discussed different situations.

\section{METHOD}

\section{A. Rationale}

Using Newton's Law of Universal Gravitational Attraction ${ }^{[3]}$, the force $(\mathrm{F})$ acted by the Star whose mass is $\mathrm{m} 2$ to the Star whose mass is $\mathrm{m} 1$ is:

$$
\mathrm{F}=\mathrm{G} \frac{\mathrm{m}_{1} \mathrm{~m}_{2}}{\mathrm{r}_{12}{ }^{2}} \bullet \frac{\overrightarrow{\mathrm{r}}}{\mathrm{r}_{12}}
$$

Based on Newton's Second Law, we have:

$$
\mathrm{F}=\mathrm{ma}
$$

\author{
W.D. Jiang* \\ Jiangsu Tianyi High School \\ China \\ *Corresponding author
}

J.H. Gao

Shanghai Centre for Bio-information Technology

China
According to the two formulas (1)、(2) above, we can draw Figure 1.

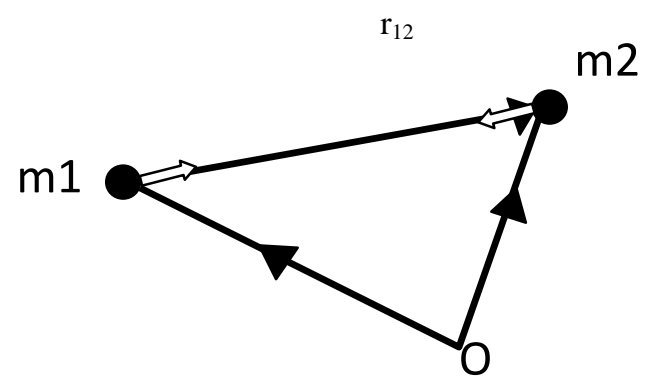

FIGURE I. THE INTERACTION FORCE BETWEEN STAR 1 AND STAR 2.

In Figure 1, we assume the mass of two stars are $\mathrm{m} 1$ and $\mathrm{m} 2$ and synthesize formula (1) and (2) and get the gravitation formula (3) and (4).

$$
\overrightarrow{\mathrm{a}}_{1}=\mathrm{G} \frac{\mathrm{M}}{\mathrm{r}_{12}{ }^{3}} \cdot \overrightarrow{\mathrm{r}}
$$

Synthesizing the situations we discussed above, we assume the three stars' masses are $\mathrm{m} 1, \mathrm{~m} 2, \mathrm{~m} 3$, and we derive the following formulas:

$$
\begin{aligned}
& \vec{a}_{1}=G \frac{m_{2} *\left(\vec{r}_{2}-\vec{r}_{1}\right)}{r_{12}{ }^{2}} \cdot \vec{r}+G \frac{m_{3} *\left(\vec{r}_{3}-\vec{r}_{1}\right)}{r_{31}{ }^{2}} \cdot \vec{r} \\
& \vec{a}_{2}=G \frac{m_{1} *\left(\vec{r}_{1}-\vec{r}_{2}\right)}{r_{12}{ }^{2}} \cdot \vec{r}+G \frac{m_{3} *\left(\vec{r}_{3}-\vec{r}_{2}\right)}{r_{32}{ }^{2}} \cdot \vec{r} \\
& \vec{a}_{3}=G \frac{m_{1} *\left(\vec{r}_{1}-\vec{r}_{3}\right)}{r_{31}{ }^{2}} \cdot \vec{r}+G \frac{m_{2} *\left(\vec{r}_{2}-\vec{r}_{3}\right)}{r_{32}{ }^{2}} \cdot \vec{r}
\end{aligned}
$$

\section{B. Difference Equation [4]}

Assuming that we know the three stars' coordinates and velocities at time $\mathrm{T}$, we can use the Difference Equations to calculate the three stars' coordinates at time $\mathrm{T}+1$ while 
considering the two-dimensional condition and using Euler Method.

$$
\left\{\begin{array}{l}
\mathrm{x}_{1}(\mathrm{t}+1)=\mathrm{x}_{1}(\mathrm{t})+\mathrm{vx}_{1}(\mathrm{t}) * \Delta \mathrm{t} \\
\mathrm{y}_{1}(\mathrm{t}+1)=\mathrm{y}_{1}(\mathrm{t})+\mathrm{vy}_{1}(\mathrm{t}) * \Delta \mathrm{t} \\
\mathrm{x}_{2}(\mathrm{t}+1)=\mathrm{x}_{2}(\mathrm{t})+\mathrm{vx}_{2}(\mathrm{t}) * \Delta \mathrm{t} \\
\mathrm{y}_{2}(\mathrm{t}+1)=\mathrm{y}_{2}(\mathrm{t})+\mathrm{vy}_{2}(\mathrm{t}) * \Delta \mathrm{t} \\
\mathrm{x}_{3}(\mathrm{t}+1)=\mathrm{x}_{3}(\mathrm{t})+\mathrm{vx}_{3}(\mathrm{t}) * \Delta \mathrm{t} \\
\mathrm{y}_{3}(\mathrm{t}+1)=\mathrm{y}_{3}(\mathrm{t})+\mathrm{vy}_{3}(\mathrm{t}) * \Delta \mathrm{t}
\end{array}\right.
$$

Also, the velocities at time $\mathrm{T}+1$ can be calculated:

$$
\left\{\begin{array}{l}
\mathrm{vx}_{1}(\mathrm{t}+1)=\mathrm{vx}_{1}(\mathrm{t})+\mathrm{m}_{2} * \mathrm{~g} *\left(\frac{\mathrm{x}_{2}(\mathrm{t})-\mathrm{x}_{1}(\mathrm{t})}{\operatorname{dist}_{12}}\right) * \Delta \mathrm{t}+\mathrm{m}_{3} * \mathrm{~g} *\left(\frac{\mathrm{x}_{3}(\mathrm{t})-\mathrm{x}_{1}(\mathrm{t})}{\operatorname{dist}_{31}}\right) * \Delta \mathrm{t} \\
\mathrm{vy}_{1}(\mathrm{t}+1)=\mathrm{vy}_{1}(\mathrm{t})+\mathrm{m}_{2} * \mathrm{~g} *\left(\frac{\mathrm{y}_{2}(\mathrm{t})-\mathrm{y}_{1}(\mathrm{t})}{\operatorname{dist}_{12}}\right) * \Delta \mathrm{t}+\mathrm{m}_{3} * \mathrm{~g} *\left(\frac{\mathrm{y}_{3}(\mathrm{t})-\mathrm{y}_{1}(\mathrm{t})}{\operatorname{dist}_{31}}\right) * \Delta \mathrm{t} \\
\mathrm{vx}_{2}(\mathrm{t}+1)=\mathrm{vx}_{2}(\mathrm{t})+\mathrm{m}_{1} * \mathrm{~g} *\left(\frac{\mathrm{x}_{1}(\mathrm{t})-\mathrm{x}_{2}(\mathrm{t})}{\operatorname{dist}_{12}}\right) * \Delta \mathrm{t}+\mathrm{m}_{3} * \mathrm{~g} *\left(\frac{\mathrm{x}_{3}(\mathrm{t})-\mathrm{x}_{2}(\mathrm{t})}{\operatorname{dist}_{32}}\right) * \Delta \mathrm{t} \\
\mathrm{vy}_{2}(\mathrm{t}+1)=\mathrm{vy}_{2}(\mathrm{t})+\mathrm{m}_{1} * \mathrm{~g} *\left(\frac{\mathrm{y}_{1}(\mathrm{t})-\mathrm{y}_{2}(\mathrm{t})}{\operatorname{dist}_{12}}\right) * \Delta \mathrm{t}+\mathrm{m}_{3} * \mathrm{~g} *\left(\frac{\mathrm{y}_{3}(\mathrm{t})-\mathrm{y}_{2}(\mathrm{t})}{\operatorname{dist}_{32}}\right) * \Delta \mathrm{t} \\
\mathrm{vx}_{3}(\mathrm{t}+1)=\mathrm{vx}_{3}(\mathrm{t})+\mathrm{m}_{1} * \mathrm{~g} *\left(\frac{\mathrm{x}_{1}(\mathrm{t})-\mathrm{x}_{3}(\mathrm{t})}{\operatorname{dist}_{31}}\right) * \Delta \mathrm{t}+\mathrm{m}_{2} * \mathrm{~g} *\left(\frac{\mathrm{x}_{2}(\mathrm{t})-\mathrm{x}_{3}(\mathrm{t})}{\operatorname{dist}_{32}}\right) * \Delta \mathrm{t} \\
\operatorname{vy}_{3}(\mathrm{t}+1)=\mathrm{vy}_{3}(\mathrm{t})+\mathrm{m}_{1} * \mathrm{~g} *\left(\frac{\mathrm{y}_{1}(\mathrm{t})-\mathrm{y}_{3}(\mathrm{t})}{\operatorname{dist}_{31}}\right) * \Delta \mathrm{t}+\mathrm{m}_{2} * \mathrm{~g} *\left(\frac{\mathrm{y}_{2}(\mathrm{t})-\mathrm{y}_{3}(\mathrm{t})}{\operatorname{dist}_{32}}\right) * \Delta \mathrm{t}
\end{array}\right.
$$

In the formulas above, $\mathrm{g}$ is the gravitational constant; dist is the distance between stars.

\section{Numerical Simulation Method (Trapezoid) [5]}

1) Principle of Euler's method. Divide the interval [a,b] into $\mathrm{n}$ parts, so the differential equation at point xi has the following form $y^{\prime}(x i)=f(x i, y(x i))$, then using the forward difference quotient to estimate and substitute for the derivative, we get:

$$
\frac{\left(\mathrm{y}\left(\mathrm{x}_{\mathrm{i}}+1\right)-\mathrm{y}\left(\mathrm{x}_{\mathrm{i}}\right)\right)}{\mathrm{h}}=\mathrm{f}\left(\mathrm{x}_{\mathrm{i}}, \mathrm{y}\left(\mathrm{x}_{\mathrm{i}}\right)\right)
$$

In this formula, $\mathrm{h}$ is step-length, the distance between each two nodes.

Therefore, we can use the values of xi and yi to calculate the value of $y \mathrm{i}+1$ :

$$
\mathrm{y}_{\mathrm{i}}+1=\mathrm{y}_{\mathrm{i}}+\mathrm{h} \times \mathrm{f}\left(\mathrm{x}_{\mathrm{i}}, \mathrm{y}_{\mathrm{i}}\right), \mathrm{i}=0,1,2, \mathrm{n}
$$

So this is how to derive the Euler's Expression. Thus, if the initial value of yi +1 is known, we can use the formula above to calculate y1 y2 y3 ......yn.

The Euler's Expression is shown below.

\%one step of the Euler method

function $\mathrm{y}=$ singlestep $(\mathrm{t}, \mathrm{x}, \mathrm{h})$

$\mathrm{y}=\mathrm{x}+\mathrm{h}^{*} \mathrm{ydot}(\mathrm{t}, \mathrm{x})$;

2) Principle of Trapezoid method. By changing the $\mathrm{f}(\mathrm{xi}, \mathrm{yi}) \mathrm{in}$ Euler's Expression with the average of $\mathrm{f}(\mathrm{xi}, \mathrm{yi})$ and $f(x i+1, y i+1)$, we get the trapezoid expression. Comparing
Euler's method and the trapezoid method, it can be shown that the latter is more precise.

\%one step of the Trapezoid method

function $\mathrm{y}=$ singlestep $(\mathrm{t}, \mathrm{x}, \mathrm{h})$

$\mathrm{u}=\mathrm{ydot}(\mathrm{t}, \mathrm{x})$;

$\mathrm{y}=\mathrm{x}+0.5 * \mathrm{~h} *(\mathrm{u}+\mathrm{ydot}(\mathrm{t}+\mathrm{h}, \mathrm{x}+\mathrm{h} * \mathrm{u}))$;

\section{RESULT AND DISCUSSION}

In all, we've investigated 6 patterns. They are Three-bodies convolving\& Three-bodies-shared-orbit, Sun Earth Mars System, Lagrange point Condition and Figure-eight Situation.

\section{A. Three-bodies convolving\& three-bodies-shared-orbit}

The parameters used in these simulations are $\{$ [the simulated time interval 0 - n(s)],[x1, vx1, y1, vy1, x2, vx2, y2, vy2, x3, vx3, y3, vy3], step size, steps per point plotted $\}$. We assume the three masses and speeds are equal. The result is shown in Figure 1.

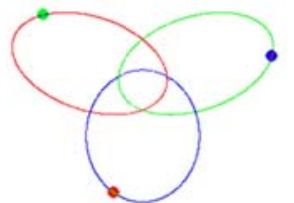

FIGURE II. THREE-BODIES CONVOLVING.

Three-bodies-shared-orbit is the transformation of Three-bodies convolving. The gravitational interaction among them is not big so the initial positions are small. The result is shown in Figure 2.

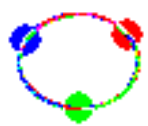

FIGURE III. THREE-BODIES-SHARED-ORBIT.

Since the gravitational interaction among Three-bodies-shared-orbit is much bigger than Three-bodies convolving, we increased the gravitational interaction, either by reducing the relative distance or by increasing the masses.

\section{B. Sun-earth-mars system}

The Sun-Earth-Mars system means a heavy large star in the middle of the circle while two lighter planets move in circular orbits. The mass ratio of the three stars was 100:1:1 and the initial positions and velocities are random. The result is shown in Figure 3.

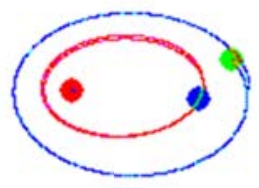

FIGURE IV. RESULT OF SUN-EARTH-MARS SYSTEM. 


\section{Lagrange point condition}

As we know, the Lagrange Point means a point in an the orbital configuration of a two-body system where a small object affected only by gravity can theoretically be stationary relative to the two larger objects. The result is shown in Figure 4.

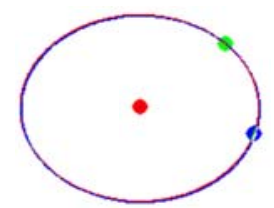

FIGURE V. PRECISE RESUlt OF LAGRANGE POINT SITUATION.

\section{Figure-eight situation}

We searched the internet and found the regular period of Figure-Eight problem. The three stars may be symmetry to centre so that we can estimate the initial position that can link them together. The result is shown in Figure 5.

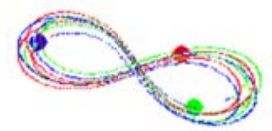

\section{FIGURE VI. FIRST RESULT OF FIGURE-EIGHT SITUATION.}

Since we desire to make the mess routines into only one precise orbit, there is a computer program can automatically emit all the inaccurate result and finally find out the only completely precise value. The result is shown in Figure 6 .

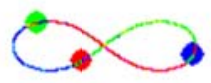

FIGURE VII. PRECISE RESULT OF FIGURE-EIGHT SITUATION.

\section{E. Sun-earth-moon system}

Since we live in the Sun-Earth-Moon System, we really want to explore this situation. Our teacher told us to use the data in reality instead of creating the ratio by ourselves. Then we searched the real masses and distance and adjusted the parameter for many times. Eventually, we found it. The result is shown in figure 7 :

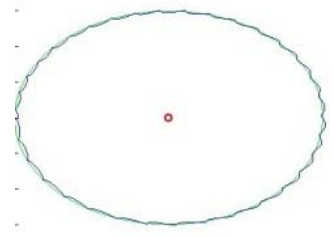

FIGURE VIII. RESULT OF SON-EARTH-MOON SYSTEM.

\section{F. Two large stars and one small companion}

We started to think about the general situation that two large stars are convolving in the middle while a tiny companion star moving around the orbit. The result is shown in figure 8:

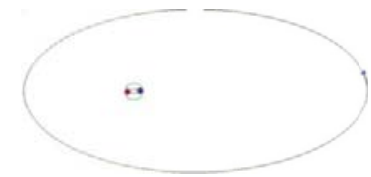

FIGURE IX. RESULT OF TWO LARGE STARS AND ONE SMALL COMPANION.

We predict that there is another condition which is two-bodies-shared-orbit in the centre and the small companion moving around them. The result is shown in figure 9:

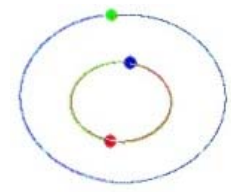

FIGURE X. RESULT OF TWO-BODIES-SHARED-ORBIT AND ONE SMALL COMPANION

\section{CHART OF PATTERN CATEgORY}

So far we synthesize all of the conditions according to the number of orbits and the magnitude of mass. The chart of pattern category is shown in Table1.

TABLE I. THREE BODIES PATTERN CATEGORY.

\begin{tabular}{|l|l|l|l|}
\hline $\begin{array}{l}\text { Three stars with } \\
\text { the same masses } \\
\text { (Three stars) }\end{array}$ & $\begin{array}{l}\text { Figure-Eight\& } \\
\text { Three-bodies-shar } \\
\text { ed-orbit }\end{array}$ & Two Orbits & Three Orbits \\
\hline $\begin{array}{l}\text { Two large one } \\
\text { small stars and } \\
\text { (Two } \\
\text { one planet) }\end{array}$ & $\begin{array}{l}\text { Three-bodies } \\
\text { convolving } \\
\text { hare-orbit and } \\
\text { one planet } \\
\text { revolve }\end{array}$ & $\begin{array}{l}\text { Onvolve planet } \\
\text { One } \\
\text { revolve }\end{array}$ \\
\hline $\begin{array}{l}\text { Two small one } \\
\text { large two } \\
\text { (One star two } \\
\text { planets) }\end{array}$ & Two-planets-s \\
hared-orbit & $\begin{array}{l}\text { Sun-Earth-Ma } \\
\text { rs }\end{array}$ \\
\hline $\begin{array}{l}\text { Large Middle } \\
\text { Small } \\
\text { (Star Planet } \\
\text { Moon) }\end{array}$ & & $\begin{array}{l}\text { Lagrange } \\
\text { point }\end{array}$ & $\begin{array}{l}\text { Sun-Earth-M } \\
\text { oon } \\
\text { Sun-Earth-Co } \\
\text { met }\end{array}$ \\
\hline
\end{tabular}

\section{REFERENCE}

[1] Changhong Dong, Zhiguo Lai, Xiaohai Yu, MATLAB, Graphics and Images Processing, Defence Industry Publishing House, pp.206 209, 2004

[2] http://www.mathworks.com/products/matlab/index.html? s_tid=gn_loc_drop

[3] Zhu Gao, Junhui Gao, Numerical Simulation For Orbit Patterns Of Two Stars, of China Education Innovation Herald, No.11, 2010

[4] High School Curriculum Text Book Physics 2, Jiangsu Education Province Press, pp. 17 21, 2010

[5] Ronghua Li, Bo Liu, The Numerical Solution of Difference Equations, Higher Education Press, pp. 107 109, 2009

[6] Jinyi Zhao, Astrophysics Mechanics, Shanghai Science and Technology Publishing House, pp.96 98, 1983 